of these principles to the design of plant and the development of processes. This preliminary work cannot be greatly curtailed, and consequently the training of a chemical engineer is bound to take longer than that of a pure chemist or an engineer. The Institution of Chemical Engineers published some years ago a scheme for a full-time degree course in chemical engineering extending over four years; but, in view of the great shortage of chemical engineers, it has been felt for some time that degree courses alone are not sufficient and that a valuable method of increasing the supply of chemical engineers would be the establishment of part-time courses. The difficulty has been to devise such courses without making them of inordinate length. The Institution has now put forward a method of instruction in the form of a pamphlet entitled "Scheme for a Part-time Course in Chemical Engineering" (pp. 23 ; London : the Institution, $1951 ; 2 s$.$) . This is described, perhaps$ optimistically, as a three year course with an "endorsement year" for entrants already holding Ordinary National Certificates in chemistry or mechanical engineering. It is quite clear, however, that the course is really one of four years, as, without the endorsement year, it would be very incomplete ; with the endorsement year, the course is admirable and, on paper at least, equivalent to the degree course. Detailed syllabuses and the approximate times spent on each subject are given, which, though only suggestions, will undoubtedly prove of great value to those who are considering the possibilities of such a course. It should be noted that the times given include laboratory work. In addition to the purely formal matter, the pamphlet abounds in brief remarks on the underlying principles of the teaching and the emphasis to be placed on different subjects ; it is worth reading for these alone.

\section{Weather Artistry}

Three recent articles by L. C. W. Bonacina in the Royal Meteorological Society's monthly periodical Weather deal with the picturesque effects of weather, especially cloudscapes. The first, "The Scenery of Devonshire in Relation to Weather and Climate" (May 1951), is a rapid tour through the coastlands, valleys and moors in sunshine, shower, frost, fog and snow. In "London's Picturesque Cloud Scenery" (November 1951) we read how, in the built-up areas of south-east England, man may play havoe with the beauties of hill and woodland, but the sky is fortunately beyond his reach. Even the pearly London smoke haze may add to the beauty of "faltering glints of silvery or golden sunlight seen to perfection as they steal across the Thames". London fogs are rather tactfully passed over. The remaining article, "Turner as a Weather Painter, a Centenary Appreciation" (July 1951), which is illustrated by reproductions of "The Wreck" and "Snowstorm", is a skilful analysis of the weather symbolism in Turner's renderings of cloud and sea, and the effects of sunshine and haze on vistas of mountains. In fact, as Mr. Bonacina points out, instantaneous detail of actual weather in paint is almost impossible for an artist to realize ; he can only reproduce the spirit of the rapidly changing scene. Turner's cloudscapes may not be perfect meteorology, but they are magnificent art.

\section{Processing Colonial Raw Materials}

IN a Colonial Office publication, "The Processing of Colonial Raw Materials", by Charlotte Leubuscher (pp. 186 ; London : H.M.S.O., 1951; 10s. net), it is pointed out that the root causes why processing industries have not developed in many tropical countries are general economic backwardness and low standards of living. Prospects for the establishment of processing industries are brightest for materials such as oilseeds and cane sugar, which have a local market or where such a market might easily be established. There is less likelihood that processing factories can be successfully established for materials such as cocon or sisal for which the markets are almost entirely outside the producing countries. Often a producing territory provides too small a basis for the development of an efficient industry. The market in this event would have to be regional, but it does not follow that the most advantageous situation for a processing industry will necessarily be in the country producing the bulk of the raw material. In other words, it is likely that the tendency for industries to be attracted by the markets where their output is sold will assert itself also in the tropics. This is exemplified by the comparatively advanced industrial development of Trinidad within the West Indian region and the industrial importance of Singapore where raw materials from the Malayan hinterland and Indonesia are processed on a large scale.

\section{Soil Survey of Great Britain: Report for 1950}

THE Soil Survey Research Board of the Agricultural Research Council has recently published report No. 3 of the Soil Survey of Great Britain (pp. $36+3$ plates ; London: H.M.S.O., 1951 ; $3 s$. net). This report summarizes the progress made during 1950 and gives brief descriptions of new series found. It also includes an obituary of Prof. G. W. Robinson, chairman of the Board, who died during the year. The broad classification of previous reports has been retained; this follows current international practice, with subdivisions to take into account differences in drainage and in the rocks from which the soils are formed. The classification is shown by tables, and this should assist in the recognition of soils developed on the same rocks in those parts of Britain which have not yet been mapped. During the year a further 327,000 acres have been surveyed, and work has continued in Lancashire, Yorkshire, Banffshire, Kincardineshire and Angus, Roxburghshire and Ayrshire. The survey of a sheet around Cambridge has been started with the view of obtaining information about the Fenland soils. The sheets covering Anglesey and the Glastonbury (Somerset) sheet have been completed and are being prepared for publication, and the Wem (Shrop. shire) sheet is in an advanced state of preparation for publication. Soil maps and reports of the north of Banffshire and the north-east of Aberdeenshire are almost ready for printing.

\section{Science Abstracting: Final Report of the Paris} International Conference

THE final report of the International Conference on Science Abstracting, convened in Paris by the United Nations Educational, Scientific and Cultural Organization during June 20-25, 1949, has now been issued (pp. $192+10$ plates. Paris : Unesco ; London : H.M.S.O., $1951 ; 12 s .3 d$. net) and gives a clear idea of studies and discussions out of which the recommendations of the Final Act of the Conference (see Nature, 164, 998; 1949) emerged; the Final Act is given in the appendixes to the report. These appendixes also include, among other documents, the 